Student Success

ISSN: 2205-0795

Volume 6, Issue 2, pp. 33-41

August 2015

\title{
Navigating VET to university: Students' perceptions of their transition to university study
}

Tracy Barber, Clare Netherton, Alicia Bettles and Amanda Moors-Mailei

University of Technology, Sydney, Australia

\section{Abstract*}

This paper examines preliminary findings from research into the transition experiences of students entering university through a VET pathway. Participants' responses obtained in an online survey are analysed to explore their perceptions of how their VET background influenced their transition, including their expectations and adjustment to university. Findings indicate that participants are largely experiencing transition as a positive experience, but in particular those who perceived their VET background as very influential on their transition have significantly higher levels of adjustment and fulfilled expectations. The survey is part of a larger research project including focus groups and interviews that will allow a deeper analysis of students' experiences. The research also aims to contribute to a deeper conceptual understanding of the transition process.

*This article was first presented at the 2015 STARS Conference in Melbourne, Australia in July 2015 and was selected via the peer review process as one of the top-rated papers. The authors have kindly given their permission to have this article published in the conference issue of the Journal and it has undergone a further review by the editors to confirm it aligns with the Journal format.

Please cite this article as:

Barber, T., Netherton, C., Bettles, A., \& Moors-Mailei, A. (2015). Navigating university: Students' VET to perceptions of their transition to university study. Student Success, 6(2), 33-41. doi: 10.5204/ssj.v6i2.289

This article has been peer reviewed and accepted for publication in Student Success. Please see the Editorial Policies under the 'About' section of the Journal website for further information.

Student Success: A journal exploring the experiences of students in tertiary education

(cc) $\mathrm{BY}$ This work is licensed under a Creative Commons Attribution 4.0 Licence. As an open access journal, articles are free to use, with proper attribution, in educational and other non-commercial settings. ISSN: 2205-0795 


\section{Introduction}

Students following a vocational education and training (VET) pathway into university comprise a significant proportion of the student intake at the University of Technology Sydney (UTS)-around $11 \%$ of commencing students in 2014. Students transitioning along VET pathways are valued for the diversity they bring to the student population, in terms of their work and life experiences, socio-economic status backgrounds, and vocational knowledge and skills.

The research literature indicates that commencing students in general need to be better prepared for university study (Christie, Tett, Cree, \& McCune, 2014). However, students entering through VET pathways experience specific hurdles and difficulties in making the transition from vocational to university education. Given the emphasis on increasing VET-university transition, there needs to be a better understanding at UTS of the learning and overall university experiences of its commencing VET students. The increasing number of studies into the VET-university student transition experience over recent years (e.g. Ambrose et al., 2013; Christie et al.; Goldingay, Hosken, Land, Barnes, \& Murphy, 2013; Griffin, 2014) indicates this situation is not unique to UTS but widespread across the sector.

The research project aims to understand the influence of entering university through a VET pathway on the student's experience of university study and life. As is the case across the higher education sector, increasing the number of students entering university through non-traditional pathways, including VET pathways, is a key element of the university's policy for widening access to equity groups. This is in line with state and national government equity recommendations and policies, including that $20 \%$ of undergraduate enrolments are students from a low socioeconomic status background by 2020 (Bradley, Noonan, Nugent, \& Scales, 2008; New South Wales Government, 2011).

The specific design of the research project also aims to address a noted gap in the literature of the student's voice in describing VET-university transition, especially students from disadvantaged backgrounds (Aird, Miller, van Megen, \& Buys, 2010; Griffen, 2014). This research project draws directly upon the voices of students who have transitioned along VET pathways into UTS, to understand their perceptions of how their VET background influenced their university experience, their adjustment, the challenges and difficulties they experienced, and what they found helped or hindered their integration into the university. The complete research project includes student focus groups and interviews that explore in more depth the themes emerging from the survey, but the scope of this paper is limited to findings from the online survey.

\section{Research context}

The research reported in this paper is part of a wider strategy at UTS to widen access to VET students and support their effective transition, retention and success. Prior to the current research project, the focus at UTS in relation to VET students had been upon widening access, primarily through acknowledging VET qualifications as the basis for admission into its courses, ${ }^{1}$ and developing credit recognition arrangements and articulation pathways between VET and university courses. In particular, the emphasis was upon developing pathways from the public TAFE sector as

\footnotetext{
${ }^{1}$ UTS accepts completed AQF diplomas and advanced diplomas and the TAFE Tertiary Preparation Certificate for entry
} into the majority of UTS courses. A small number of courses consider Certificate IV qualifications for admission. 
strategy for widening access to students from low SES backgrounds ${ }^{2}$.

UTS implemented a range of pathways-building activities between 2011-2014 including: expanding credit recognition arrangements between TAFE qualifications and UTS courses in targeted areas; providing more detailed and accessible information for TAFE students prior to enrolment to inform their decision-making about university pathways and options, and undertaking direct outreach to TAFE students promoting the opportunities for using their qualification to access university education. UTS and TAFE NSW, particularly Sydney TAFE Institute, established a number of partnerships and projects to facilitate these actions.

UTS is now moving beyond the access and early transition focus for VET pathways students, to questioning the longer term impact of entering through VET pathways. Findings from this research will contribute to reviewing and strengthening the university's structures, processes and activities to support VET students from pre-enrolment through to study completion.

\section{Conceptualising transition}

Given the research project's focus beyond early transition to VET students' ongoing experience of university study, it provides an opportunity to explore conceptualisations of transition within the higher education setting, and also taken-for-granted terms such as "pathways." Gale and Parker (2011) note that student transition projects rarely explicitly consider what constitutes transition, despite the fact that different conceptualisations lead to different ideas about managing or supporting transition. They and other writers including Christie et al. (2014) advocate a more dynamic interpretation of students' transition processes, and extending the focus beyond early transition to include for example transition prior to university entry and the latter years of undergraduate study. Such analyses could reveal the connections between learning, participation in practice and identity across the lifetime of a student's degree program.

Gale and Parker (2011, 2012) provide a three stage typology of student transition. The first category, Transition as Induction, draws upon metaphors such as "journey" or "pathway" to portray transition as sequentially defined periods of adjustment, with the student moving from one institutional and/or disciplinary context to another, learning and adapting to the organisation's practices, structures, routines and culture through activities such as orientation and information provision. The second and third conceptions of student transition are Transition as Development qualitatively distinct stages of maturation along trajectories of transformation, involving a shift in identity and Transition as Becoming - a perpetual series of fragmented movements involving whole-of-life fluctuations. While transition may involve anxiety and risk, transitions can also lead to profound change and provide impetus for new learning. Transition occurs in response to turning points and significant events as well as through setbacks and periods of routine and stability.

Gale and Parker stress the mutuality of agency and structure in transition - it is "the capacity to navigate change (emphasis in original) [which includes] the resources to engage with change, without having full control over and/or knowledge about what the change involves. [Navigation] alludes to the mutuality of agency and structure in transitions [and] evokes agency in relation to structure" (2011, p. 25).

\footnotetext{
${ }^{2}$ It is noted that the effectiveness of VET qualifications in increasing low SES student representation in higher education is actually questionable, given that low SES students are overrepresented in low level VET qualifications which do not provide university access, and under-represented in diplomas and advanced diplomas which do provide access (Naylor, Baik \& James, 2013; Wheelahan, 2009).
} 
Gale and Parker's conceptualisation is useful in framing the interpretation of participants' experiences of the transition process at UTS, in particular students' agency in transition and transition as an ongoing process extending throughout the university experience. As well as providing a framework for analysing students' transition experiences in this research, it is helpful in reviewing and reflecting upon current approaches to transition at UTS; for example, the way in which "pathways,", with its suggestion of linear advancement, has become the accepted term for describing the movement from VET to university.

\section{Factors influencing VET students' transition to university}

Transitioning from vocational to university education requires students to make adjustments socially, pedagogically, financially and emotionally, a process even more complicated for those from disadvantaged backgrounds (Griffen, 2014). Factors identified as affecting the transition of TAFE students are:

- differences in aims, learning and assessment approaches between VET and higher education sectors, specifically the vocational focus and competency-based training and assessment processes in the VET sector compared with the theoretically focussed, curriculum model in higher education;

- academic literacy issues, including skills in information locating, referencing, interpreting and usage, high level writing skills, note taking, volume and complexity of reading material, and comprehension of discipline-specific technical prose;

- perceived higher academic standards and levels of expectations at university;

- repetition of TAFE content in the first year of TAFE students' university study;
- a greater focus at university on student autonomy and self-regulation;

- cultural differences in the two sectors' traditions and practical expressions;

- status hierarchies, with TAFE perceived as inferior, and the option students take if they are "not good enough" to get into university;

- contrasts in staff-student interactions and relationships;

- time-management difficulties in combining study, work and family commitments;

- credit recognition issues including potential academic and social impacts of missing out on orientation, induction into the discipline, and knowledge and academic scaffolding designed to support first year students' successful transition into second year;

- administrative issues (e.g., registering for tutorials); and

- coping with the online environment(Ambrose et al., 2013; Beddie, 2014; Cameron, 2004;; Griffen, 2014; Jackson, Dwyer, Paez, Byrnes, \& Blacker, 2010; ; PhillipsKPA, 2006; Watson, 2008).

The complete research project investigates participants' responses in the context of these findings, although this paper only focusses on factors relating to adjustment and expectations.

\section{Method}

A survey was designed to investigate the transition experience of students who entered UTS through a VET pathway, with key components including questions investigating: 
the influence of participants' VET backgrounds on their university experience; how well participants feel they have adjusted to being a student at UTS; the extent to which the courses studied at UTS have met their expectations; support services they have utilised; and their suggestions for improving support for transitioning students based on their own experiences. Participants were also asked to report the extent to which other factors may be influencing their university experience, including financial constraints or difficulties, personal or family commitments, employment commitments, family support for university study, confidence in academic ability, difficulties with academic writing tasks, and motivation to study. A copy of the survey is available from the lead author

Participants were asked to respond to survey items related to influence of VET background or other factors by selecting a response from the following five point scale: "not at all influential", "slightly influential", "somewhat influential", "very influential", and "extremely influential". For measures of student adjustment to university and the extent to which the course studied had met expectations, participants were asked to indicate their level of agreement with survey item statements by selecting a response from the following five point scale: "strongly disagree", "disagree", "neither agree nor disagree", "agree", "strongly agree".

The survey was developed in Survey Monkey for online distribution. All students who had entered UTS through a VET pathway and were undertaking first or second year study were emailed, invited to participate in the study, and provided with the link.

Survey responses were collated and coded for analysis, with non-parametric statistical analysis used due to non-normality of the distribution of data and considerable variation in group size. For example, the Mann-Whitney U-Wilcoxon rank sum test was used to determine differences between participant groups reporting high or low influence of TAFE or college background on university experience. All significance tests were two-tailed, and all analysis was performed using SPSS 22 .

\section{Results}

\section{Sample}

One hundred and twenty-four (9.2\%) of the 1,351 students who received the survey link returned a completed survey. The majority of respondents $(83.7 \%, \quad n=103)$ reported commencing their studies at UTS either one

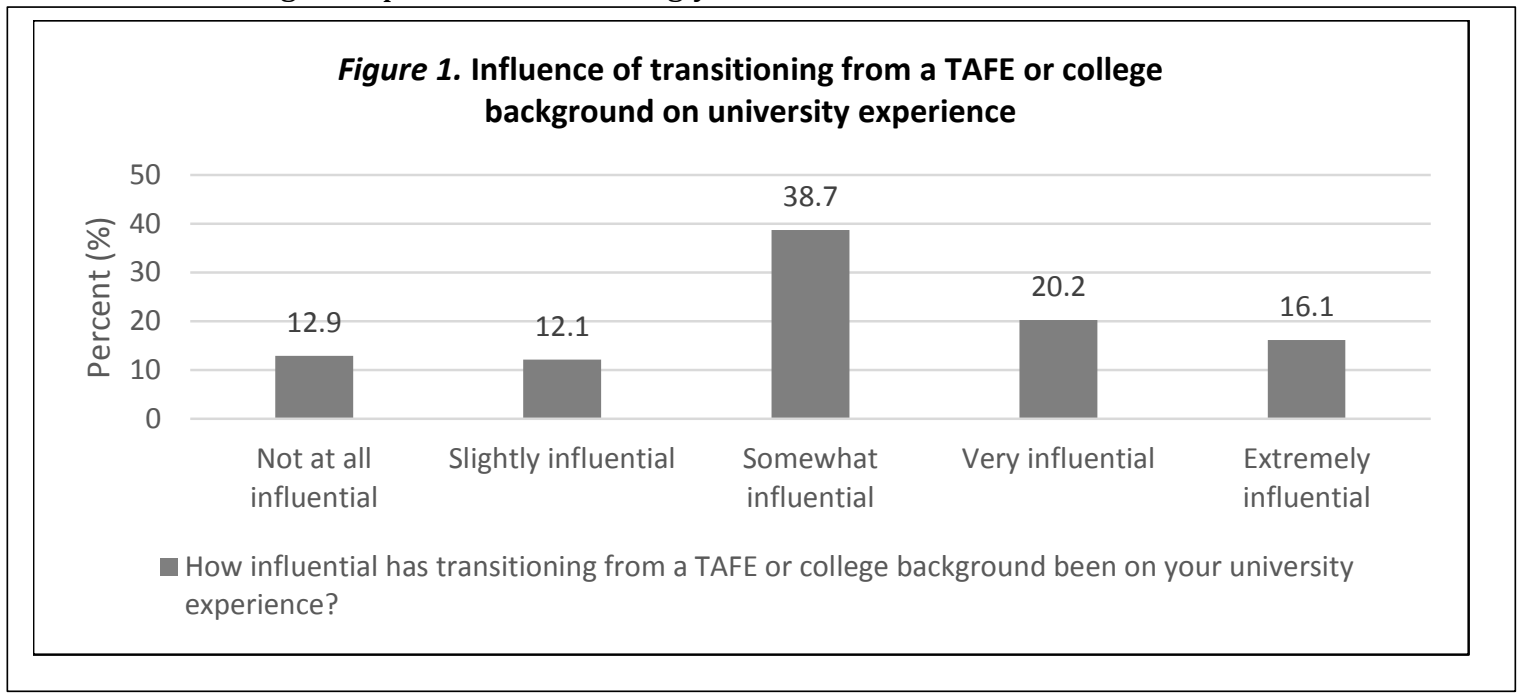


$(45.5 \%, \mathrm{n}=56)$ or two $(38.2 \%, \mathrm{n}=47)$ years previously, while a smaller number reported commencing three or more years previously (16.3\%, n=21). Almost all students who completed the survey had completed their VET studies at either a Technical and Further Education (TAFE) Institute $(80.8 \%, \mathrm{n}=97)$ or a private training college $(19.2 \%, \mathrm{n}=23)$ prior to transitioning to university. The sample included students who had previously completed Diploma (56.9\%, $\mathrm{n}=70)$ and Advanced Diploma qualifications $(17.9 \%, n=22)$, as well as a range of Certificate qualifications including the Tertiary Preparation Certificate $(25.2 \%, \mathrm{n}=31)$.

The sample was well represented by both male and female students $(45.1 \%, \mathrm{n}=55 ; 54.0 \%$, $\mathrm{n}=67^{3}$ ), and respondents ranged in age from 19 to 55 years (mean age $=27.7 \pm 8.7$ years). Over $70 \%(72.7 \%, \mathrm{n}=88)$ of respondents indicated they were currently employed, with most of these students $(83.0 \%, n=73)$ undertaking either part-time or casual work. Approximately half of the sample $(50.8 \%, \mathrm{n}=62)$ reported receiving some form of benefit such as Newstart, Austudy and Carer's Payment.

\section{Influence of VET background on the university experience}

Participants were asked to indicate how influential transitioning from a TAFE or college background had been on their university experience by selecting a response on a five point scale. The proportion of participants selecting each response option is shown in Figure 1.

Influence of TAFE or college background data were recoded to create "higher" influence (response options "very" or "extremely influential") and "lower" influence (response options "not at all", "slightly" and "somewhat influential") groups. Recoded data resulted in $36.3 \%(n=45)$ of the sample categorised in the "higher" influence of TAFE or college background on university experience group and $63.7 \%(n=79)$ categorised in the "lower" influence group.

The "higher" and "lower" influence of VET background on university experience groups did not differ significantly by age, gender, faculty, employment or benefit receipt, and there were no differences between the two cohorts in relation to the self-reported influence of personal or family commitments, family support for university study, confidence in academic ability, difficulty with academic writing tasks, and motivation to study. However, participants reporting "higher" influence of their VET backgrounds also reported a greater influence of financial constraints or difficulties (124 cases, $\mathrm{z}=-2.67$, $\mathrm{p}<.01)$ and employment or work commitments (124 cases, $\mathrm{z}=-2.64, \mathrm{p}<.01$ ) on their university experience than participants reporting "lower" influence of their VET backgrounds.

\section{Influence of VET background and adjustment to university}

Results suggest that overall, participants are adjusting positively to life at university. Nearly $90 \%$ of the sample $(87.1 \%, \mathrm{n}=108)$ agreed they are adjusting well to being a university student. Positive findings emerged for measures of social adjustment in particular, with $77.5 \%(\mathrm{n}=96)$ agreeing they feel confident they fit in at university and $79.8 \%(\mathrm{n}=99)$ agreeing they have made friends at UTS. The majority of participants report good academic adjustment to university, with $76.6 \%(\mathrm{n}=95)$ agreeing they feel confident asking questions and contributing to class discussion, $67.7 \%(\mathrm{n}=84)$ agreeing that they are coping well with the academic demands of their course and $56.4 \%(\mathrm{n}=70)$ agreeing they are managing their time well.

Measures of adjustment to university were analysed by VET influence groups. Analysis showed several significant differences in

\footnotetext{
3 Two respondents did not indicate their gender.
} 
adjustment to university reported by the "higher" and "lower" VET influence on university experience groups. Compared with participants in the "lower" VET influence group, participants who indicated that their VET background had been "very" or "extremely influential" on their university experience reported significantly higher levels of agreement with the following statements: I am adjusting well to being a university student (124 cases, $\mathrm{z}=-3.54, \mathrm{p}<.001$ ), I feel confident that I fit in at university (124 cases, $\mathrm{z}=-2.99, \mathrm{p}<.01), I$ have made friends at UTS (124 cases, $\mathrm{z}=-3.44$, $\mathrm{p}<.01$ ), and ' feel confident asking questions and contributing to class discussion (124 cases, $\mathrm{z}=-$ $2.09, \mathrm{p}<.05$ ).

\section{Influence of VET background and student expectations of their university course}

Results show a positive response from participants to their courses studied at university, with $85.5 \%(n=106)$ agreeing their course was the right choice for me. The majority of participants $(76.7 \%, \mathrm{n}=95)$ agree that overall, their course has met their expectations, and there are positive findings for measures of expectation related to course interest and enjoyment. Results show $64.5 \%(n=80)$ of participants agreeing the course is more interesting than expected, and 53.2\% $(\mathrm{n}=66)$ agreeing the course is more enjoyable than expected, despite only $12.9 \%(\mathrm{n}=16)$ agreeing that the course is easier than expected. The extent to which courses met student expectations was variable in relation to teaching, with $46.8 \% \quad(\mathrm{n}=58)$ agreeing the quality of teaching is better than expected, and $36.3 \%(n=45)$ agreeing the 'amount of feedback from teachers is less than expected'.

Measures of student expectations of their university course were also analysed by VET influence groups. There were significant differences between the 'higher' and 'lower' VET influence groups on these measures of student expectations. Compared with participants in the 'lower' VET influence group, participants who indicated that their VET background had been "very" or "extremely influential" on their university experience reported significantly higher levels of agreement with the following statements: The course is more interesting than I expected $(124$ cases, $\mathrm{z}=-2.90, \mathrm{p}<.01)$, The course is more enjoyable than I expected (123 cases, $\mathrm{z}=-2.76$, $\mathrm{p}<.01)$, The quality of teaching is better than I expected (123 cases, $\mathrm{z}=-1.99, \mathrm{p}<.05$ ), The course I have chosen was the right choice for me $(124$ cases, $\mathrm{z}=-2.45, \mathrm{p}<.05$ ), and Overall, the course has met my expectations (122 cases, $\mathrm{z}=-2.79$, $\mathrm{p}<.01$ ).

\section{Discussion and conclusion}

The results indicate that, overall, students entering through VET pathways are reporting positive experiences in relation to adjustment and expectations. Students are reporting that their VET studies generally prepared them well for university across a number of areas: their VET experience gave them the encouragement, motivation and confidence to continue studying, a sense of direction for their future, provided familiarity with the university course content, and the necessary skills including time management, academic writing, independent learning, communication and presentation skills. Representative comments were:

I feel that studying Aged Care at TAFE prior to beginning my university degree helped me to quickly adjust to the coursework, particularly in the first year. This was mainly due to having been exposed to many of the concepts in the course prior to studying at university.

When at TAFE we were encouraged to use our Diploma to further our studies and to work hard. Our teachers encouraged us to strive to be the best we could be and shape out a career for ourselves.

With the skills provided to me at TAFE, I am able to confidently ask questions and publicly 
discuss my thoughts on a certain topic in class with little to no problems, also I have made a lot of close friends. Overall TAFE heavily influenced my university experience positively.

A strong sense of gratitude for the support they had received at TAFE permeated participants' responses, with one participant commenting that I attribute my success to the base they gave me and I will be forever grateful for their belief in me.

Participants' responses convey that for many, both undertaking VET studies, then entering university, were major turning points in their lives. For example, one participant noted that TAFE was the best place to restart my study life, demonstrating Gale and Parker's (2011) position that transitions can lead to profound change and be an impetus for new learning.

Participants did however also identify difficulties in adjusting to university, including noting the lower levels of individual support at university, difficulty adjusting to large lectures and increased work load. For example:

At TAFE, the teachers are more involved with the students than lecturers and tutors at university, they take responsibility for student performance, due to smaller class sizes. This leads to feeling respected, compared to uni, where you feel like a number/just another student in a huge education factory....Also, each class at TAFE has the same students, therefore relationships are formed, compared to uni, there is a lack of relationship, causing fear, anxiety and loneliness, which negatively affects performance and engagement.

Gale and Parker (2012) note that transition may involve anxiety and risk, and this clearly comes through in the participant's statement, as does a sense of powerlessness. The comment reflects previous findings regarding differing levels of student autonomy in the VET and university sectors - TAFE teachers take responsibility for student performance but at university this student feels unseen, another number in a factory. There is a sense of lack of agency, of being ill-equipped to navigate the change required in cross-sectoral movement. These experiences will be further investigated through the research project and contribute to review of existing access and support processes for transitioning VET students.

It is noteworthy that $36.3 \%$ of students felt that their VET background had a high influence on their transition to university, and that these participants also had overall higher levels of adjustment and fulfilled expectations. The written comments of the higher and lower influence cohorts will be examined further and explored in focus groups to more fully understand their experiences. This will include understanding how perceived influence of VET background shifts over students' time at university, and other factors unique to this cohort - for example, whether they differ in terms of academic engagement or success, and whether there are particular qualities of their participants' VET experiences or university preparation before commencement that could be utilised to support other students making the transition to university.

\section{References}

Aird, R., Miller, E., van Megen, K. \& Buys, L. (2010). Issues for students navigating alternative pathways to higher education: Barriers, access and equity. Adult learner social inclusion project, QUT/Griffith University. Brisbane, Australia. Retrieved from http://www.bridgetostudy.com.au/about/research.j sp

Ambrose, I., Bonne, M., Chanock, K., Cunnington, C., Jardine, S. \& Muller, J. (2013). "Like catching smoke": Easing the transition from TAFE to university. Journal of Academic Language and Learning, 7(2), 120-131. Retrieved from http://journal.aall.org.au/index.php/jall/article/vie $\underline{w} / 257$

Beddie, F. (2014). A differentiated model for tertiary education: Past ideas, contemporary policy and future possibilities. Adelaide, Australia: NCVER. Retrieved from

http://www.ncver.edu.au/publications/2748.html

Bradley, D., Noonan, P., Nugent, H., \& Scales, B. (2008) Review of Australian higher education. Final report. Canberra, Australia: Commonwealth of Australia. 
Retrieved

http://hdl.voced.edu.au/10707/44384

Cameron H. (2004). Paving the Way? The path to Uni for TAFE Students. Dealing with Diversity, Brisbane, 8th Pacific Rim First Year in Higher Education: Conference Proceedings, Eds. Duncan Nulty and Noel Meyers. Retrieved from http://trove.nla.gov.au/version/166839906

Christie, H., Tett, L., Cree, V. \& McCune, V. (2014). "It all just clicked": a longitudinal perspective on transitions within university. Studies in Higher Education. doi: 10.1080/03075079.2014.942271

Gale, T \& Parker, S. (2011). Good practice report: Student transition into higher education. The Australian Learning and Teaching Council. Retrieved from http://hdl.voced.edu.au/10707/214056

Gale, T. \& Parker, S. (2012). Navigating change: a typology of student transitions in higher education. Studies in Higher Education. doi: 10.1080/03075079.2012.721351

Goldingay, S., Hosken, N., Land, C., Barnes, P. \& Murphy, K. (2013). That social side of things: Students' experiences of social and physical place. In Frielick, S., Buissink-Smith, N., Wyse, P., Billot, J., Hallas, J \& Whitehead, E. (Eds.) Research and Development in Higher Education: The Place of Learning and Teaching, 36, 164-174. Retrieved from http://hdl.handle.net/10536/DRO/DU:30056840

Griffen, T. (2014). Disadvantaged learners and VET to higher education transitions. NCVER, Adelaide. Retrieved from http://hdl.voced.edu.au/10707/318642

Jackson, A., Dwyer, C., Paez, D., Byrnes, J. \& Blacker, J. (2010). Transforming vision into reality: the Integrated Articulation and Credit Transfer Project. AVETRA 2010. Retrieved from http://hdl.voced.edu.au/10707/49430

Naylor, R., Baik, C. \& James, R. (2013). Developing a Critical Interventions Framework for advancing equity in Australian higher education. Centre for the Study of Higher Education, The University of Melbourne. Retrieved from http://hdl.voced.edu.au/10707/259740

New South Wales Government (2011). NSW 2021: A plan to make NSW number one. Retrieved from: http://www.nsw.gov.au/sites/default/files/nsw 20 21_plan.pdf

PhillipsKPA. (2006). Giving credit where credit is due: A national study to improve outcomes in credit transfer and articulation from Vocational and Technical Education to Higher Education, Stage 1 Report. Commonwealth Department of Education, Science and Training.

Watson, L. (2008). Improving the experience of TAFE award-holders in higher education. International
Journal of Training Research, 6(2), 40-53. doi: 10.5172/ijtr.6.2.40

Wheelahan, L. (2009). What kind of access does VET provide to higher education for low SES students? Not a lot. National Centre for Student Equity in Higher Education Launch and Forum, University of South Australia. Retrieved from http://hdl.handle.net/11343/28889 